\title{
Metacognitive Awareness, Procrastination and its Impact on Students' Academic
}

\author{
Performance \\ * Ghazal Khalid Siddiqui, Assistant Professor \\ ** Saira Taj, Assistant Professor \\ *** Farah Maqsood, MPhil Education
}

\begin{abstract}
Metacognitive awareness is awareness about perception which further involves declaration, procedure as well as condition aspects, whereas, procrastination involves the action of delaying or postponing something. Both metacognition and procrastination are interrelated and can affect academic performance. Academic performance is an indicator of students' learning at any educational level but several factors can have an impact on it. This investigation was mainly conducted to determine the impact of metacognitive awareness and procrastination on the academic performance of learners in universities. The nature of this study was quantitative and a survey approach was adopted for this study. The sample of the study was comprised of twelve hundred graduates and postgraduates from universities by utilizing cluster sampled methods. To find the awareness of students' metacognition the MAI (Schraw \& Denison, 1994) was applied because of its appropriateness as well as for finding the procrastination behavior of students the Aitken Procrastination Inventory (Aitken, 1982) was applied in this investigation. Academic performance was determined through students' previous GPA (grade point average). The findings of this investigation revealed that metacognition and procrastination significantly affect the academic performance of university students.
\end{abstract}

Keywords: Metacognition, Procrastination, Students, Universities, Academic Performance Introduction

Metacognition shows an integral part in the educational life of learners. It is the consciousness of the learner's thinking manners. In Flavell's view (1979), for managing a learner's thought processes a higher degree of awareness of his or her cognitive and academic learning procedures is required, this type of awareness is called metacognition. In general, two fundamental constituents of metacognition are awareness and control of perception. Awareness of perception further involves declaration, procedure as well as condition aspects. While control of perception encompasses policies to plan, monitor, and evaluate the cognitive actions (Baker \& Brown, 1984; Schraw \& Dennison, 1994).

Researches conducted on metacognition revealed that learners' comprehension of their thought processes has a significant and positive correlation to their performance in learning activities (Mevarech \& Fridkin, 2006; Vrugt \& Oort, 2008). Learners plan strategies before starting learning to accomplish learning tasks without a haphazard situation. To monitor their learning is another important element of successful performance. For determining to what extent they have achieved their learning goals, learners evaluate their learning performance. These are the essential strategies of successful learning. Yet, this phenomenon is not solely responsible for success in learning.

Many of the learners having a higher awareness of their metacognition processes are not capable to accomplish their academic assignments timely (Lau \& Chan, 2003). Due to this failure in the accomplishment of academic work, their performance in academic tasks is automatically obstructed. This failure is due to the procrastinating behavior of learners. Procrastination means completion of tasks when the appropriate time is passed; the time allotted for the accomplishment of different activities (Silver, 1974; Silver \& Sabini, 1981).

Research investigations revealed that there is a significant role of students' metacognition in academic performance. It was found out from the results that learners' metacognition positively

* University of Education Lahore Email: ghazalkhalid@ue.edu.pk

** Lahore College for Woman University Lahore Email: saira.zainab.taj@gmail.com

*** University of Education Lahore Email: farahmaqsood162@gmail.com 
affects educational accomplishment (Taehee, Shinho \& Heejun, 1998; Coutinho, 2007). Learners availing high scores in educational tasks possessed high metacognition strategies. Another opinion is that learners' thought processes are the predictors of their academic success or failure. Research studies displayed that students who get good grades and perform greater than average in academic activities have a good understanding of their metacognition. On the other side, learners who get poor scores and perform lower than average in academic assignments have a poor understanding of their metacognition processes (Dunning, Johnson, Kruger \& Ehrlinger, 2003; Young \& Fry, 2008).

Narang and Saini in 2013 conducted a research investigation to analyze the role of metacognitive awareness in the educational achievement of learners. Elementary and secondary school students of Ludhiana State were investigated for their performance. Results of this analysis displayed that many of the contributors were performed greater than expected because of their awareness of thinking processes.

Research findings (Rezvan, Ahmad \& Abedi, 2006; Sarvanakumar \& Mohan, 2007) have also recognized that preparation about metacognition processes and strategies affect learning activities of individuals positively as well as slow learners can also get an advantage from these strategies. Parcel (2005) conducted a research investigation to find the role of metacognitive awareness in learners' academic performance. The findings concluded that when learners were trained on metacognitive strategies through virtual instruction, their performance in educational activities was increased when evaluated through post-test.

Several studies revealed that awareness of learner's metacognition is significantly related to their procrastination. Several researches were conducted on the role of metacognition awareness in the procrastinating behavior of students at different academic levels. Findings represented a negative association concerning metacognition awareness and procrastination (Wolters, 2003; Howell \& Watson, 2007). It was concluded that procrastination increased when students were unaware of their thinking processes and strategies (planning, monitoring, and evaluating). Much of the studies (McCown, Petzel \& Rupert, 1987; Johnson \& Bloom, 1995; Ferrari \& Dovidio, 2000; Ferrari, 2001; Schouwenburg, Lay, Pychyl \& Ferrari, 2004) analyzed that individuals with procrastinating characteristics are not capable to plan and organize their learning and therefore unable to complete the educational assignments within the specific time. It was concluded that learners were little aware of their metacognitive strategies for completing educational responsibilities.

A study by Fernie and Spada (2008) found that metacognition played a significant negative role in the procrastinating behavior of learners. It was found out that when students' awareness of their metacognition was high their procrastination tendency was low. Additionally, the results of various empirical researches were pointed that the enhancement in group counseling process based on the cognitive-behavioral approach and aimed to reduce the academic procrastination occurs with changes in thinking, feeling, and behavior (Stead, Shanahan, \& Neufeld, 2010; Rice, Neimeyer, \& Taylor, 2011; Ozer, Demir, \& Ferrari, 2013). Because of this, it may be concluded that maladaptive cognitive processes have negative effects on the tendency of procrastination in academic settings, though, adaptive cognitive processes, for example, metacognitive awareness that is an effective term in directing cognition and monitoring cognitive processes and outcomes, have positive impacts on the academic procrastination. In other words, higher metacognitive awareness may reduce the tendency of academic procrastination.

Several studies based on academic procrastination were conducted among university students (Lee, 2005; Odaci, 2011). The procrastinating behavior of learners in the accomplishment of educational assignments is the cause of their low academic success. Learners do not focus on the important tasks due to diverse actions and consequently, they face hurdles in completion of curricular activities (Ferrari, Johnson \& McCown, 1995). Learners who could not be successful in the completion of learning projects, not that they are unintelligent or dull. This is because of delaying the important tasks and assignments. According to the findings of a research investigation (Akinsola, Tella \& Tella, 2007) conducted to examine the role of procrastination in learners' academic performance, procrastination played an important and significant role in students' learning. Findings revealed that there is a negative effect of procrastination on academic task accomplishment. The procrastinating behavior of learners reduced their academic performance.

It was found out from a research study that the procrastinating behavior of learners in the accomplishment of educational activities, meeting the deadlines of assignments, and preparation for 
exams were the reasons for lower academic performance (Zimmerman, Bandura \& MartinezPons, 1992). To compare the academic performance of procrastinators with non-procrastinators, a research study was conducted. It was revealed from the results that procrastination had a substantial influence on an individual's educational accomplishment, besides when correlation was examined it was found out that procrastination is negatively correlated with educational accomplishment (Semb, Glick \& Spencer, 1979; Lay, 1986; Beswick, Rothblum \& Mann, 1988; Wesley, 1994).

Procrastinating behavior does not affect the performance of low achievers significantly. It was found out from the results of a research study that students who scored lower in scholastic aptitude tests also performed inefficiently in exams, however they attended classes (Beck, Koons \& Milgrim, 2000).

\section{Conceptual Framework}

The current study is structured on Flavell's theory of metacognition and Schraw \& Dennison's model of metacognitive strategies. And procrastinating phenomenon is grounded on Aitken's model (1982). Much more researches were conducted on metacognition and performance in learning as well as on procrastination's effect on achievement at altered levels. The current investigation concentrated on analyzing the impact of metacognitive awareness and procrastination on the academic performance of graduates and postgraduates of universities, Lahore district. Therefore investigation was conducted to meet the following objectives:

1. To determine the impact of metacognitive awareness and procrastination on the academic performance of graduates and postgraduates, and

2. To observe the impact of metacognitive awareness on procrastination of graduates and postgraduates in universities.

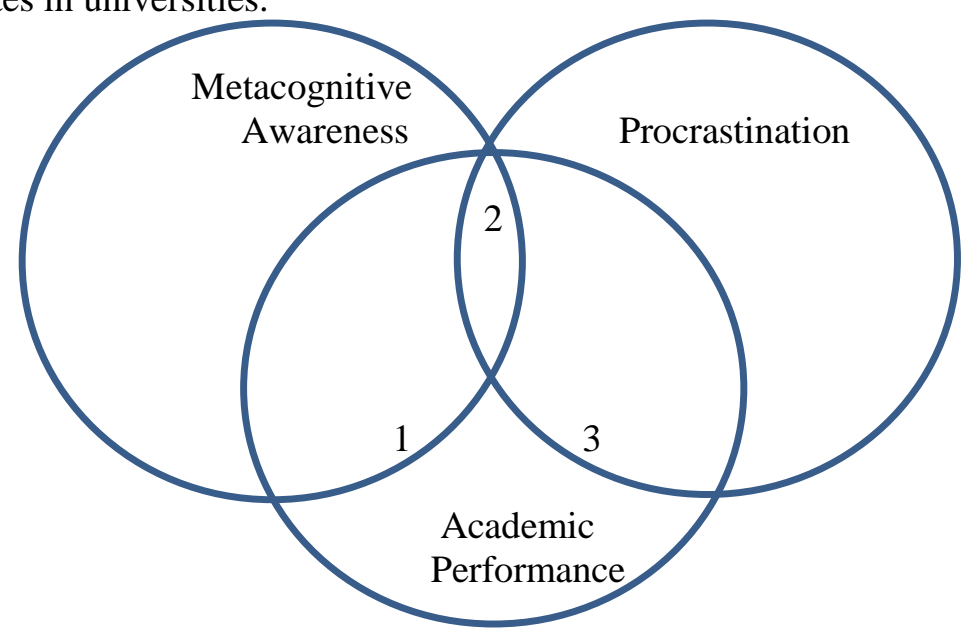

Diagram 1 Impact of metacognitive awareness and procrastination on academic performance

$1,2,3$ are groupings of these three variables; 1 . Greater metacognitive awareness results in greater academic performance, 2. Greater metacognitive awareness lower procrastination tendency, 3. A higher degree of procrastination behavior tends to be lesser academic performance.

\section{Research Methodology}

The nature of this study was quantitative and a survey design was used to collect data. The population of this investigation was the graduates and postgraduates from government as well as private universities, Lahore. 1200 students were sampled from the total population utilizing the cluster sampled method. This sample comprised male and female graduates and postgraduates from different departments in government and private universities of Lahore. Participants were enrolled in four years program of instruction. The details of the sample selected for this analysis is given below in table1.

Table 1. Detail of the selected sample

\begin{tabular}{lcc}
\hline & Number of Students & Percentage \\
\hline Department & 360 & 30 \\
Natural Sciences & 360 & 30 \\
Social Sciences & 300 & 25 \\
$\quad$ Linguistics & 180 & 15 \\
$\quad$ Management Sciences & & \\
Gender & 439 & 37 \\
$\quad$ Male &
\end{tabular}




\begin{tabular}{ccc}
\hline \hline Female & 761 & 63 \\
Previous GPA & & \\
$<3.20$ & 345 & 29 \\
$3.21-3.70$ & 606 & 50 \\
$>3.70$ & 249 & 21 \\
Total & 1200 & 100 \\
\hline
\end{tabular}

Two instruments were used to collect data from the participants. First Instrument that was applied in the present analysis was the metacognitive awareness inventory organized and standardized by Schraw and Dennison (1994). Alpha level of MAI was 0.93 determining the reliability of the instrument which was significant. The second Instrument that was used in this study was the Aitken procrastination inventory (Aitken, 1982). It comprised of nineteen statements responding on a fivepoint Likert scale. Alpha level of API was 0.75 displayed significantly the reliability of the instrument. Academic performance was determined through students' previous GPA (grade point average). Participants provided their responses through questionnaires which consisted of demographic variables information and statements of MAI and API. Once data were collected, it were entered into SPSS version 21 for analysis and statistical calculation purposes.

Table 2 Pearson Correlation among metacognitive awareness, procrastination and academic performance (GPA)

\begin{tabular}{|c|c|c|c|c|}
\hline Variables & GPA & $\begin{array}{l}\text { Metacognitive } \\
\text { Awareness }\end{array}$ & $\begin{array}{l}\text { Knowledge about } \\
\text { Cognition }\end{array}$ & $\begin{array}{l}\text { Regulation of Procrastination } \\
\text { Cognition }\end{array}$ \\
\hline GPA & - & - & & \\
\hline Metacognitive Awareness & $.109^{* * *}$ & 1 & - & \\
\hline $\begin{array}{l}\text { Knowledge about } \\
\text { Cognition }\end{array}$ & $.107^{* *}$ & $.916^{* * *}$ & 1 & - \\
\hline Regulation of Cognition & $.092^{* *}$ & $.978^{* * *}$ & $.820^{* *}$ & 1 \\
\hline Procrastination & $-.107^{* *}$ & $-.379^{* *}$ & $-.345^{* *}$ & $-.331^{* *}$ \\
\hline
\end{tabular}

** significant at 0.01

Table displays a significant correlation of metacognitive awareness with GPA and knowledge and regulation about cognition also correlate with GPA. The findings reveal that metacognition awareness has a positive impact and correlation with academic performance which means that students with higher metacognitive awareness show greater academic performance at graduate and postgraduate levels. It is also evident from the results that students' awareness of their metacognition processes has a significant and negative correlation with procrastination at the graduate and postgraduate levels. The higher metacognition awareness level results in a lower level of procrastinating behavior.

Table 3 Regression Model: Impact of Metacognitive awareness and procrastination on academic performance

\begin{tabular}{|c|c|c|c|c|c|c|}
\hline \multicolumn{7}{|c|}{ ANOVA } \\
\hline \multicolumn{2}{|c|}{ Model } & Sum of Squares & $\mathrm{df}$ & Mean Square & $\mathrm{F}$ & $\mathrm{p}$ \\
\hline & Regression & 1.990 & 1 & 1.990 & 13.770 & $<.001$ \\
\hline \multirow[t]{2}{*}{1} & Residual & 173.161 & 1198 & .145 & & \\
\hline & Total & 175.151 & 1199 & & & \\
\hline \multirow[t]{3}{*}{2} & Regression & 3.019 & 2 & 1.509 & 10.496 & $<.001$ \\
\hline & Residual & 172.132 & 1197 & .144 & & \\
\hline & Total & 175.151 & 1199 & & & \\
\hline
\end{tabular}

Table 3 shows analysis results that there is a significant impact of metacognitive awareness as well as of procrastination on academic performance $\mathrm{F}(1,1198)=10.496, \mathrm{p}<.001$.

Table 4 Analysis of regression coefficients

\begin{tabular}{|c|c|c|c|c|c|c|}
\hline \multicolumn{7}{|c|}{ Coefficients } \\
\hline \multirow{2}{*}{\multicolumn{2}{|c|}{ Model }} & \multirow{2}{*}{\multicolumn{2}{|c|}{$\begin{array}{l}\text { Unstandardized } \\
\text { Coefficients }\end{array}$}} & \multirow{2}{*}{$\begin{array}{l}\text { Standardized } \\
\text { Coefficients } \\
\text { Beta }\end{array}$} & \multirow{2}{*}{$\begin{array}{l}\mathrm{t} \\
\text { Value }\end{array}$} & \multirow[t]{2}{*}{ Significance } \\
\hline & & & & & & \\
\hline \multirow{5}{*}{$\begin{array}{l}1 \\
2\end{array}$} & (Constant) & 3.641 & .076 & & 47.813 & $<.001$ \\
\hline & Procrastination & -.103 & .028 & -.107 & .3 .711 & $<.001$ \\
\hline & (Constant) & 3.337 & .137 & & 24.415 & $<.001$ \\
\hline & Procrastination & -.079 & .029 & -.082 & -2.734 & .006 \\
\hline & $\begin{array}{l}\text { Metacognitive } \\
\text { awareness }\end{array}$ & .059 & .022 & .080 & 2.674 & .008 \\
\hline
\end{tabular}


Note $\mathrm{R}^{2}=.01$

Stepwise regression was conducted to see the impact. Analysis result shows that procrastination has a significant impact on students' performance $(\beta=-.079, \mathrm{p}<.006)$ and metacognitive awareness has a significant impact on students' performance $(\beta=.059, \mathrm{p}=.008)$.

Table 5 Regression Model: Impact of metacognitive awareness on procrastination

\begin{tabular}{lllllll}
\hline \multicolumn{2}{l}{ ANOVA } & \multicolumn{6}{l}{} \\
\hline Model & & Sum of Squares & df & Mean Square & F & p \\
\hline & Regression & 26.851 & 1 & 26.851 & 200.352 & $<.001$ \\
1 & Residual & 160.555 & 1198 & .134 & & \\
& Total & 187.407 & 1199 & & & \\
\hline
\end{tabular}

Table 5 shows analysis results that there was a significant impact of metacognitive awareness on procrastination $\mathrm{F}(1,1198)=200.352, \mathrm{p}<.001$.

Table 6 Analysis of regression coefficient

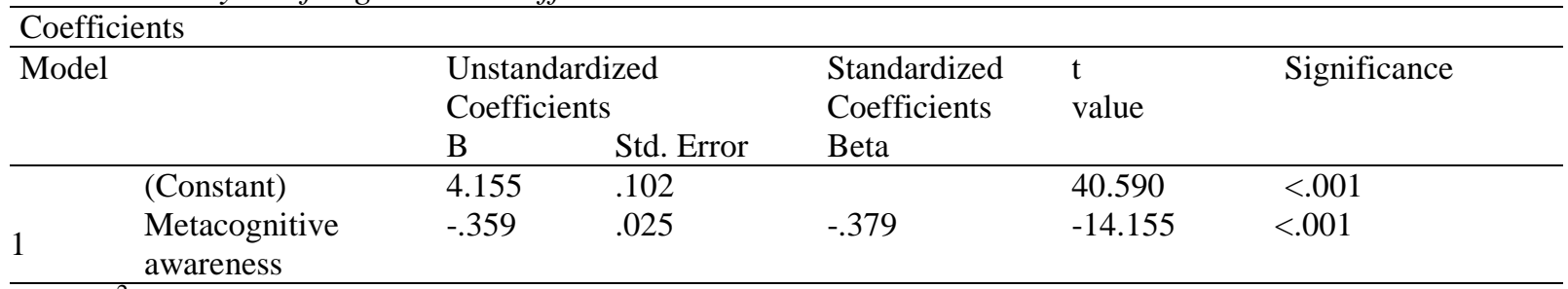

Note $\mathrm{R}^{2}=.14$

Stepwise regression was conducted and the results show that metacognitive awareness has a significant impact on procrastination $(\beta=-.359, \mathrm{p}<.001)$.

\section{Conclusion and Discussion}

This research work aimed at examining the impact of metacognitive awareness and procrastination on academic performance in universities, Lahore district. Findings confirm awareness of students' metacognition is significantly and positively correlated to their academic performance as well as it is consistent with few earlier works in review of related literature (Taehee et.al, 1998; Coutinho, 2007). It would thus be able to be reasoned that the learners who utilize metacognitive methodologies are more fruitful contrasted with the ones who don't, and educators can assume a significant job to build up these strategies in the learners. At the point when a learner talks through a theme, he is depicting his intuition cycles to himself and his friends. Learners ought to distinguish about the information they have or don't have during the beginning of learning new themes and this should be possible utilizing a self-soliciting approach toward the start of any classes.

The findings show that academic performance and procrastination of students are negatively and significantly correlated and it is consistent with few earlier works in review of related literature (Beswick et al., 1988; Wesley, 1994 and Akinsola et al., 2007). From this finding, it is evident that students who show procrastination in submitting assignments, in completion of educational tasks, and other works perform poorly in the assessments. It was found out that students' awareness of metacognition and procrastination are negatively and significantly interrelated, and it is consistent with a few of earlier works in review of related literature (Wolters, 2003; Schouwenburg, Lay, Pychyl and Ferrari, 2004; Howell and Watson, 2007)).

Results show that there is a significant impact of students' awareness of metacognition on academic performance $\mathrm{F}(1,1198)=10.496, \mathrm{p}<.001$ and the outcomes of this research work are consistent with several earlier works in the review of related literature (Bond, 2003; Rezvan et al, 2006; Saravanakumar \& Mohan, 2007). It is critical to discover and comprehend the connections between metacognitive awareness and educational achievement as it could be utilized to help to prepare projects to show learners metacognitive strategies and procedures that help increase their educational accomplishment. Results could likewise be utilized to adjust showing strategies in colleges to address learning issues and higher strategies of learners. It was also found out that students' procrastination behavior has a significant impact on academic performance and these outcomes are consistent with few earlier works in the review of related literature (Beck, et al, 2000). In conclusion, metacognitive awareness has a significant impact on students' procrastination in universities, Lahore district, and these outcomes are consistent with earlier works in the review of related literature (Fernie \& Spada 2008). 


\section{Suggestions and Implications}

It was suggested to train learners at different educational levels in utilizing their thinking processes and improve their metacognition preparation practices. Minimizing the chances of procrastinating behavior of students is crucial for improvement in academic performance.

From the preceding results, for future researches, it might be beneficial to research other universities or colleges as well as in many other disciplines and other aspects, to observe the impact of socio-economic status, and utilizing additional comprehensive and cultural aspects regarding examination and correlation of metacognition awareness, procrastination, and academic performance. Moreover, including other exploration strategies could likewise be a decent method to examine this association. For instance, research investigators can utilize qualitative exploration techniques, such as requesting that contributors keep a diary about their scholarly life, which would later fill in as an information point for investigation. Additionally, taking interviews could be another investigation technique, through which investigators could intentionally pose inquiries that they are keen on.

For researchers who are keen on leading investigations in related regions, more exploration regarding the causes of academic procrastination and techniques to increase metacognition awareness ought to be conducted. This may prompt activity investigations about procrastinating behavior because the reason for individuals to contemplate the negative impacts of procrastinating behavior is to stop its happening. For instance, the conceptual distinction between learners' achievement could be identified with the instructor's part in their educational life. Educators who give out stricter cut-off time have more noteworthy opportunities for reducing procrastinating behavior, while instructors who don't have severe cut-off time may make learners delay. This outcome could be utilized to illuminate teachers to overcome the happening of delaying, figured this ought to be seen from the viewpoint of culture.

\section{References}

Akinsola, M. K., Tella, A., \& Tella, A. (2007). Correlates of academic procrastination and mathematics achievement of university undergraduate students. Eurasia Journal of Mathematics, Science \& Technology Education, 3(4), 363-370.

Baker, L., \& Brown, A. L. (1984). Metacognitive skills and reading. Handbook of reading research, 1(353), V394.

Beck, B. L., Koons, S. R., \& Milgrim, D. L. (2000). Correlates and consequences of behavioral procrastination: The effects of academic procrastination, self-consciousness, self-esteem, and self-handicapping. Journal of social behavior and personality, 15(5), 3.

Beswick, G., Rothblum, E.D. \& Mann, L. (1988). Psychological antecedents of student procrastination, Australian Psychologist, 23, 207-217.

Coutinho, S. A. (2007). The relationship between goals, metacognition, and academic success. Educate , 7(1), 39-47.

Dunning, D., Johnson, K., Ehrlinger, J., \& Kruger, J. (2003). Why people fail to recognize their incompetence. Current directions in psychological science, 12(3), 83-87.

Fernie, B. A., \& Spada, M. M. (2008). Metacognitions about procrastination: A preliminary investigation. Behavioral and Cognitive Psychotherapy, 36(3), 359-364.

Ferrari, J. R. (2001). Procrastination as self- regulation failure of performance: effects of cognitive load, self- awareness, and time limits on 'working best under pressure'. European Journal of Personality, 15(5), 391-406.

Ferrari, J. R., \& Dovidio, J. F. (2000). Examining behavioral processes in indecision: Decisional procrastination and decision-making style. Journal of Research in Personality, 34(1), 127137.

Ferrari, J. R., Johnson, J. L., \& McCown, W. G. (1995). Procrastination research. In Procrastination and Task Avoidance (pp. 21-46). Springer, Boston, MA.

Flavell, J. H. (1979). Metacognition and cognitive monitoring: A new area of cognitivedevelopmental inquiry. American psychologist, 34(10), 906.

Howell, A. J., \& Watson, D. C. (2007). Procrastination: Associations with achievement goal orientation and learning strategies. Personality and Individual Differences, 43(1), 167-178.

Johnson, J. L., \& Bloom, A. M. (1995). An analysis of the contribution of the five factors of personality to variance in academic procrastination. Personality and Individual Differences, 18(1), 127-133. 
Lau, K. L., \& Chan, D. W. (2003). Reading strategy use and motivation among Chinese good and poor readers in Hong Kong. Journal of Research in Reading, 26(2), 177-190.

Lay, C. H. (1986). At last, my research article on procrastination. Journal of research in personality, 20(4), 474-495.

Lee, E. (2005). The relationship of motivation and flow experience to academic procrastination in university students. The Journal of Genetic Psychology: Research and Theory on Human Development, 166(1), 5-15. DOI: 10.3200/GNTP.166.1.5-15

McCown, W., Petzel, T., \& Rupert, P. (1987). Personality correlates and behaviors of chronic procrastinators. Personality and Individual Differences, 11, 71-79.

Mevarech, Z., \& Fridkin, S. (2006). The effects of IMPROVE on mathematical knowledge, mathematical reasoning, and meta-cognition. Metacognition and learning, 1(1), 85-97.

Narang, D., \& Saini, S. (2013). Metacognition and academic performance of rural adolescents. Studies on Home and Community Science, 7(3), 167-175.

Odaci, H. (2011). Academic self-efficacy and academic procrastination as predictors of problematic internet use in university students. Computers \& Education, 57(1), 1109-1113.

Ozer, B. U., Demir, A., \& Ferrari, J. R. (2013). Reducing academic procrastination through a group treatment program: A pilot study. Journal of Rational-Emotive \& Cognitive-Behaviour Therapy, 31(3), 127-135.

Parcel, W. J. (2005). The effect of embedded metacognitive prompts and probes on students' awareness in a multimedia lesson for elementary school students (pp. 1-79). University of San Diego and San Diego State University.

Rezvan, S., Ahmad, S. A., \& Abedi, M. R. (2006). The effects of metacognitive training on the academic achievement and happiness of Esfahan University conditional students. Counselling Psychology Quarterly, 19(4), 415-428.

Rice, K. G., Neimeyer, G. J., \& Taylor, J. M. (2011). Efficacy of coherence therapy in the treatment of procrastination and perfectionism. Counseling Outcome Research and Evaluation, 2(2), 126-136.

Sarvanakumar, A., \& Mohan, S. (2007). Entrancing student's achievement in science through metacognitive orientation and attention activation an experimental study. Experiment in Education, 3(8), 1-18.

Schouwenburg, H. C., Lay, C. H., Pychyl, T. A., \& Ferrari, J. R. (2004). Counseling the procrastinator in academic settings. American Psychological Association.

Schraw, G., \& Dennison, R. S. (1994). Assessing metacognitive awareness. Contemporary educational psychology, 19(4), 460-475.

Semb, G., Glick, D. M., \& Spencer, R. E. (1979). Student withdrawals and delayed work patterns in self-paced psychology courses. Teaching of Psychology, 6(1), 23-25.

Silver, M. \& Sabini, J. (1981). Procrastination, Journal for the Theory of Social Behaviour, 11, 207221.

Silver, M. (1974). Procrastination, Centerpoint, 1, 49-54.

Stead, R., Shanahan, M. J., \& Neufeld, R. W. (2010). "I'll go to therapy, eventually": Procrastination, stress, and mental health. Personality and individual differences, 49(3), 175-180.

Taehee, N., Shinho, J., \& Heejun, L. (1998). The use of cognitive and metacognitive strategies of elementary school students in the learning and testing situations. Journal of Seoul National University, 18 (3), 327-336.

Vrugt, A., \& Oort, F. J. (2008). Metacognition, achievement goals, study strategies, and academic achievement: pathways to achievement. Metacognition and Learning, 3(2), 123-146.

Wesley, J. C. (1994). Effects of ability, high school achievement, and procrastinatory behavior on college performance. Educational and Psychological Measurement, 54(2), 404-408.

Wolters, C. A. (2003). Understanding procrastination from a self-regulated learning perspective. Journal of Educational Psychology, 95(1), 179.

Young, A. \& Fry, J. (2008). Metacognitive awareness and academic achievement in college students, Journal of the Scholarship of Teaching and Learning, 8(2), 1-10.

Zimmerman, B. J., Bandura, A., \& Martinez-Pons, M. (1992). Self-motivation for academic attainment: The role of self-efficacy beliefs and personal goal setting. American educational research journal, 29(3), 663-676. 